
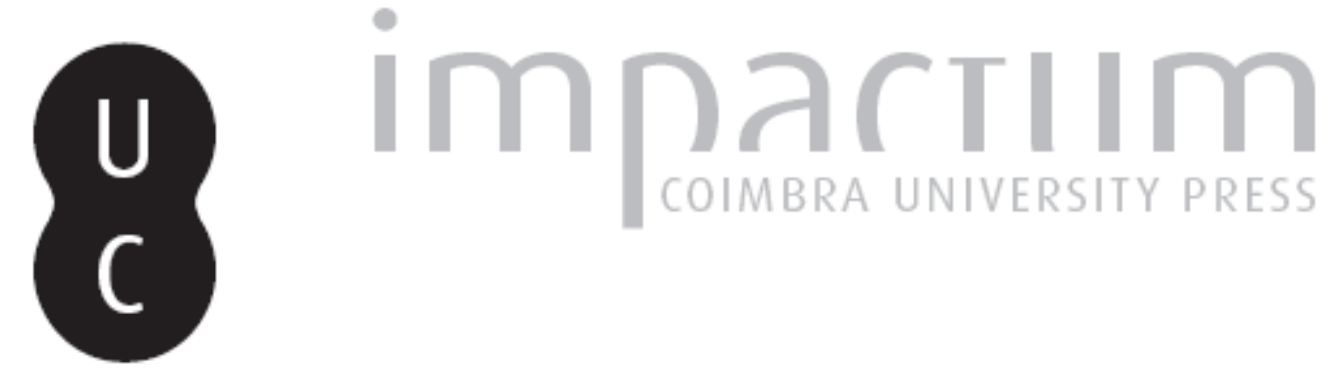

(Des)ilusão europeia ou oportunidade, tal Fénix renascida?
Autor(es): $\quad$ Almeida, Rita Guimarães Fialho d'
Publicado por: Centro de Informação Europe Direct de Aveiro; Centro de Estudos Interdisciplinares do Século XX

URL

persistente:

URI:http://hdl.handle.net/10316.2/39342

DOI:

DOI:http://dx.doi.org/10.14195/1647-6336_13_11

Accessed : $\quad$ 26-Apr-2023 10:55:52

A navegação consulta e descarregamento dos títulos inseridos nas Bibliotecas Digitais UC Digitalis, UC Pombalina e UC Impactum, pressupõem a aceitação plena e sem reservas dos Termos e Condições de Uso destas Bibliotecas Digitais, disponíveis em https://digitalis.uc.pt/pt-pt/termos.

Conforme exposto nos referidos Termos e Condições de Uso, o descarregamento de títulos de acesso restrito requer uma licença válida de autorização devendo o utilizador aceder ao(s) documento(s) a partir de um endereço de IP da instituição detentora da supramencionada licença.

Ao utilizador é apenas permitido o descarregamento para uso pessoal, pelo que o emprego do(s) título(s) descarregado(s) para outro fim, designadamente comercial, carece de autorização do respetivo autor ou editor da obra.

Na medida em que todas as obras da UC Digitalis se encontram protegidas pelo Código do Direito de Autor e Direitos Conexos e demais legislação aplicável, toda a cópia, parcial ou total, deste documento, nos casos em que é legalmente admitida, deverá conter ou fazer-se acompanhar por este aviso.

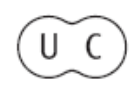


DEBATER

A EUROPA

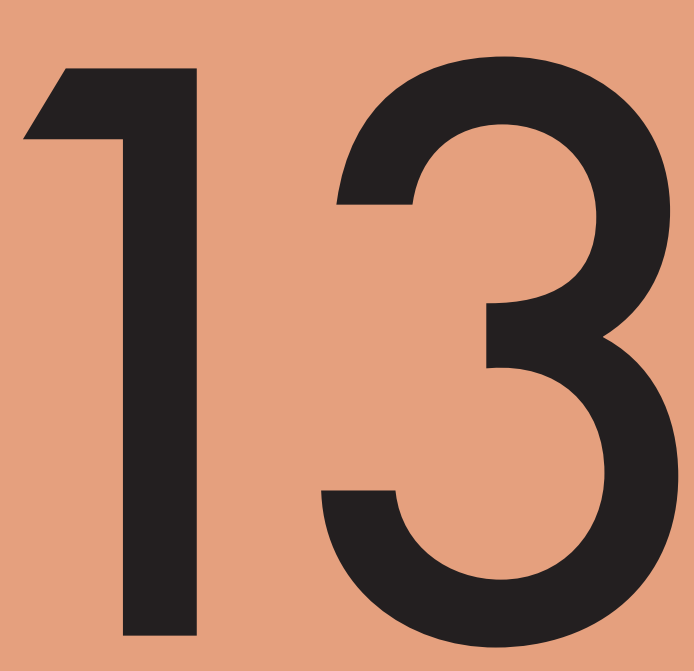

jul-dez 2015
A (DES) CONSTRUÇÃO DA EUROPA
(1939-1945)
(DE) CONSTRUCTING EUROPE (1939-1945) 


\title{
(Des)ilusão europeia ou oportunidade, tal Fénix renascida?
}

\author{
Rita Guimarães Fialho d' Almeida \\ Doutoranda FDUC \\ E-mail: ritalmeida_84@hotmail.com
}

\section{Resumo}

Numa altura em que a Europa ameaça fragmentar-se e o fracasso do projecto europeu aparece como uma possibilidade, questiona-se sobre se a União Europeia terá ainda alguma coisa a oferecer ante a suposta inexistência de alternativas ou poderá, ao invés, 'renascer das cinzas', tal imagem de Fénix renascida da mitologia grega. Com o presente texto propomo-nos chamar a atenção para dados aspectos essenciais em torno da problemática em apreço e lançar alguns argumentos para o debate sobre a Europa, a democracia e a cidadania europeia, bem como sobre a aproximação dos cidadãos às instituições da União.

Palavras-chave: Sociedade de Risco; Globalização; Modelo Social Europeu; Cidadania e Democracia Europeias; Europeização

\begin{abstract}
At a time when Europe threatens to break up and the failure of the European Project appears as a possibility, questions are raised on whether the European Union will still have something to offer at the alleged lack of alternatives or can, instead, 'rise from the ashes', such as the Image of Phoenix, reborn from Greek mythology. With this paper, we intend to draw the attention to important aspects around this issue and give some arguments for the debate on Europe, democracy and European citizenship, as well as on the level of proximity of citizens towards the European Union institutions.
\end{abstract}


Keywords: Society of Risk; globalization; European Social Model; European citizenship and democracy; Europeanization

'A experiência não é o que nos acontece; é o que fazemos com aquilo que nos acontece'

(Aldous Huxley)

\section{Indrodução}

Numa altura em que a Europa ameaça fragmentar-se face à tão falada crise do euro e à reacção hesitante por parte de diversos quadrantes políticos, ante a previsão de um crescimento económico desigual nos próximos anos entre os seus membros, a aparente inevitabilidade da manutenção e mesmo reforço da prossecução de medidas restritivas dos direitos sociais, os desafios impostos pelo alargamento da União ${ }^{1}$ e o dilema, por alguns sentido, entre o ficar e o partir da zona euro, o fracasso do projecto europeu aparece como uma possibilidade, questionando-se sobre se a União Europeia terá ainda alguma coisa a oferecer perante a suposta inexistência de alternativas ou poderá, ao invés, 'renascer das cinzas', tal imagem de Fénix renascida da mitologia grega.

Este assunto apresenta inquestionável importância e actualidade. Os discursos em torno da problemática sucedem-se, ora estribados em posições extremas, ora intermédias; por vezes, demasiado apaixonados e/ou emotivos, sem qualquer suporte científico, outras apoiados em dados (mais ou menos) precisos.

Dificuldade, quanto a nós, primeira, prende-se com a diversidade de linguagem e lógica discursiva empregue naqueles elóquios, apresentando-se esta como daquelas problemáticas que reclamam o cruzamento de várias áreas do saber como sejam, designadamente, a Economia, a Sociologia, as Ciências Políticas e o Direito, que correspondendo à nossa área de formação, compreensivelmente, não deixará de estar presente, de modo mais expressivo, nas nossas deambulações.

\footnotetext{
${ }^{1}$ Por brevidade da exposição este aspecto não será, por nós, abordado, remetendo-nos aqui para a análise feita por WEYDERT, Jean; BÉROUD, Sophie - 'O Futuro da Europa'. Porto: Colecção Que futuro?, Ambar, 2002, pp. 209-225 e MONGIARDIM, Maria Regina - 'O Alargamento da União Europeia - Novos Vizinhos'. Lisboa: Prefácio, 2004.
} 
Feita a advertência, o presente trabalho, sem ter a pretensão de esgotar o tema em apreço, almeja uma reflexão e análise oportunas dalguns aspectos, que pensamos ser essenciais, aludindo, do mesmo passo, aqui e ali, aos resultados e soluções que foram sendo avançados pela literatura, nacional e estrangeira, tida por nós, como relevante e pertinente neste domínio.

Não obstante a natureza hercúlea da tarefa, em razão da interacção entre as diversas matérias aqui tratadas, cuja cabal compreensão exige a sua percepção, não como compartimentos estanques, antes conexos, intentámos dividir a nossa exposição em duas partes: na primeira, sob o título 'União Europeia ante o advento da nova modernidade', analisaremos o conceito de sociedade de risco, assim como o de globalização e respectivos desafios, terminando com a referência ao actual contexto de falência do modelo social europeu; na segunda parte, a que demos a epígrafe de 'Renascer das cinzas', seguiremos, primeiro, de perto, atenta a importância da respectiva fundamentação no debate ora empreendido, a proposta de Habermas, que ante o aparente colapso do ideário europeu vem reclamar mais Europa, seguindo-se depois uma abordagem mais profunda acerca da construção da cidadania e democracia europeias, assim como das respostas à crise do modelo social europeu e papel decisivo do Direito. Terminaremos com o epílogo, onde faremos uma súmula dos principais dados a reter da nossa exposição que, conforme advertimos, certamente não esgotará o debate, antes lançará algumas 'achas para a fogueira', incitando à reflexão.

Com efeito, se com o presente artigo tivermos conseguido chamar a atenção para dados aspectos essenciais em torno da problemática em apreço e lançado alguns argumentos para o debate sobre a Europa, a democracia e a cidadania europeia, bem como sobre a aproximação dos cidadãos às instituições da União, teremos o nosso objectivo por alcançado.

\section{União Europeia ante o advento da nova modernidade}

\subsection{Conceito de sociedade de risco}

A passagem da sociedade feudal e agrária para a capitalista e industrial determinou uma viragem no mundo ocidental, estabelecendo o advento da modernidade 
uma nova forma de produção e distribuição de bens e uma nova forma de relações entre os homens.

Essa modernidade industrial desenvolveu-se profundamente vindo a sofrer uma nova guinada e alcançar uma condição de 'modernidade reflexiva', um estado em que o mundo é dotado de consciência do seu próprio estatuto. Agora, a reflexividade aparece como um dado estrutural, como uma componente da sociedade, não já como elemento cognitivo das pessoas.

Neste contexto, os elementos centrais são os da incerteza e da distribuição da decisão sobre os riscos entre todos, o que faz com que vivamos em um mundo onde 'o futuro coloniza o presente', posto que qualquer desgraça que possa vir a ocorrer, ocorre ainda antes, porquanto antecipada em uma série de manifestações, que nos obrigam a viver, agindo sempre em relação a elas.

O advento da nova modernidade opera, por conseguinte, mudanças radicais na política, economia e comportamento, na medida em que a produção social de riqueza faz-se acompanhar, cada vez mais, de uma produção social de riscos da instabilidade dos mercados às catástrofes ambientais e ao terrorismo, não correspondendo agora essa distribuição dos riscos às diferenças sociais, económicas e geográficas da típica primeira modernidade, circunstâncias que não deixarão naturalmente de ser tidas em conta pela União, aquando da tomada de decisões.

Ademais, o desenvolvimento da ciência e técnica não poderia mais dar conta do controlo dos riscos que contribuiu decisivamente para criar, riscos esses que geram consequências graves para a saúde humana e meio ambiente, desconhecidas a longo prazo e que, quando descobertas, tendem a ser irreversíveis ${ }^{2}$.

Este conceito de sociedade de risco cruza-se directamente com o de globalização, aparecendo agora os riscos como democráticos, afectando nações e classes sociais e sem respeitar fronteiras de nenhum tipo ${ }^{3}$.

\subsection{Globalização e seus desafios}

\footnotetext{
${ }^{2}$ Pense-se, nomeadamente, nos riscos ecológicos, químicos, nucleares e genéticos, produzidos industrialmente, externalizados economicamente, individualizados juridicamente, legitimados cientificamente e minimizados politicamente.

${ }^{3}$ Para maiores desenvolvimentos acerca do conceito de sociedade de risco, v. BECK, Ulrich 'Risk Society. Towards a New Modernity'. London: Theory, Culture \& Society Series, Sage, 1992.
} 
Embora o processo de globalização haja gerado um mundo com um nível de riqueza sem precedentes, além de o desenvolvimento acelerado de novos conhecimentos e tecnologias, cobrindo um vasto leque de áreas científicas e saberes tecnológicos, a par da influência dos meios audiovisuais de comunicação de massas e da aceleração e generalização dos movimentos de pessoas, directa ou indirectamente motivados por este processo, terem permitido que ideias e ideais circulassem cada vez mais facilmente, muitos são os males que assombram a opulência sem precedentes do mundo em que vivemos. Entre estes, contam-se a pobreza extrema, a destituição e a marginalização sociais, a privação de direitos básicos, a carência de oportunidades, a opressão e a insegurança económica, política e social, que se apresentam, conforme preconiza AMARTYA, como variedades de privação de liberdade, compartilhando a mesma natureza ${ }^{4}$.

Neste contexto, a globalização, mais concretamente as consequências que dela decorrem, transportam consigo a indagação sobre a capacidade dos Estados garantirem, por si só, o desenvolvimento social e económico e mesmo a democracia e a justiça, concorrendo os processos de globalização para a erosão do poder e autoridade dos Estados.

4 Para SEN, Amartya - 'O desenvolvimento como liberdade'. Lisboa: Gradiva, 2003, o desenvolvimento é essencialmente um processo de expansão das liberdades reais de que as pessoas desfrutam. Segundo o modelo proposto, o alargamento da liberdade é perspectivado simultaneamente como fim primeiro e o princípio meio do desenvolvimento, respectivamente, o papel constitutivo e o papel instrumental da liberdade no desenvolvimento. $O$ primeiro concerne às liberdades concretas para $\mathrm{O}$ enriquecimento da vida humana. O segundo, ao invés, refere-se ao modo como os diferentes tipos de direitos, oportunidades e habilitações contribuem para o alargamento da liberdade humana em geral, promovendo o desenvolvimento, apontando o Autor para cinco tipos de liberdade instrumental, a saber: 1) as liberdades políticas, onde se incluem os direitos civis, no respeitante à liberdade de escolha por parte das pessoas sobre quem deve governar e segundo que princípios, além dos direitos de fiscalização e crítica dos governantes através de uma imprensa livre e actuante; 2) os dispositivos económicos, que compreendem as oportunidades de que os indivíduos dispõem para utilizar os recursos económicos, para fins de consumo, de produção ou de troca; 3 ) as oportunidades sociais, que contemplam os dispositivos que as sociedades organizam, designadamente, em favor da educação e dos cuidados de saúde, com influência na liberdade concreta dos indivíduos para viverem melhor; 4) as garantias de transparência, que se referem à necessidade de uma pessoa esperar sinceridade na sua relação com outras pessoas, instituições e com o próprio Estado, e; 5) a providência social, que proporciona uma rede de protecção social para obstar a que população afectada se veja reduzida a uma miséria abjecta, incluindo-se aqui dispositivos como o subsídio de desemprego e prestações suplementares. Na perspectiva do Autor, tais liberdades não apenas permitem ao indivíduo aumentar a sua capacidade da sua condição de agente, como se reforçam umas às outras, apresentando-se a sua afirmação como um factor a favor, e não contra, o crescimento económico, entendimento que não podemos deixar de sufragar. Senão vejamos: uma sociedade onde a educação assuma o papel devido pode aspirar a receber empregos melhor pagos; do mesmo passo, a transparência gera maior confiança nos investidores que, por isso, investem mais. Citando COWPER, William apud SEN, Amartya - 'O desenvolvimento como liberdade', cit., p. 304: 'A liberdade tem para mostrar milhares de encantos / Que os escravos, ainda que contentes, nunca saberão'. 
Ademais, embora não apresente ainda consequências tão incisivas como a europeização $^{5}$, a verdade é que a globalização não deixa de agitar as fundações da ordem mundial, abrindo caminho a uma mais complexa forma de organização política e de governação, colocando-se aqui a questão de saber até que ponto está a construir-se uma nova legitimidade e, porventura, uma nova legalidade transnacional.

A noção de globalização obriga-nos então a analisar as formas emergentes de legalidade e legitimidade internacionais e a inquirir até que ponto, na ausência de um verdadeiro direito global, estas se adequam à necessidade de regular uma economia e sociedade globalizadas ${ }^{6-7}$.

Seja como for, constituindo a globalização um conjunto recíproco de processos, a União Europeia não pode limitar-se assim a «responder» àquela, posto que é hoje um instrumento e expressão dela, apresentando-se esta como a principal ideia a reter neste ponto. Desta feita, não parece excessiva e/ou despropositada a afirmação de que a globalização apresenta-se, agora, como um bem e um mal necessários, com cuja existência havemos de nos ajustar.

\subsection{Falência do modelo social europeu}

${ }_{6}^{5}$ Sobre o processo de europeização, cf. infra, ponto 2.4.

6 Neste sentido, BARROSO, J. M. Durão - 'O interesse nacional e a globalização'. In TEIXEIRA, Nuno Severiano (coord.) - 'O interesse nacional e a globalização'. Lisboa: Edições Cosmos, Instituto da Defesa Nacional, 2000, pp. 131-132, sustenta ser a globalização 'o processo através do qual, de modo crescente e cada vez mais rápido (...) se generalizam no plano internacional trocas com maior amplitude e com maior profundidade. (...) trocas de carácter económico, comercial, financeiro e de investimento, (...) informacional e cultural e também de carácter tecnológico. De algum modo, este conjunto introduz novos equilíbrios na relação dos Estados no sistema internacional e também - e este é que é o aspecto novo e decisivo - dentro dos próprios Estados e na relação destes com as respectivas sociedades'. Perfilhando idêntica perspectiva, MURTEIRA, Mário - 'Globalização - Pela invenção dum tempo global e solidário'. Lisboa: Quimera, 2003, p. 54, considera a globalização como o 'processo que tem conduzido ao condicionamento crescente das políticas económicas nacionais pela esfera megaeconómica, ao mesmo tempo que se adensam as relações de interdependência, dominação e dependência entre os actores transnacionais e nacionais, incluindo os próprios governos nacionais que procuram pôr em prática as suas estratégias no mercado global'.

7 Para maiores desenvolvimentos quanto às consequências da globalização, v. BARRETO, António; LEITE, António Nogueira; DOLLAR, David; GYIMAH-BOADI, E.; MAYOR, Federico; FUKUYAMA, Francis; ESPADA, João Carlos; SAMPAIO, Jorge; SOETE, Luc; BARBOSA, Manuel Pinto; MOREIRA, Marcílio Marques; JOHNSTON, Michael; WALLE, Nicolas van de; JOHNSON, Pierre Marc; BALDWIN, Robert. E; MCKINNON, Ronald; REBELO, Sérgio; ROSE-ACKERMAN, Susan; MACHADO, Víctor de Sá; ANDERSON, Walter Truett - 'Globalização, Desenvolvimento e Equidade'. Lisboa: Fundação Calouste Gulbenkian, Publicações Dom Quixote, 2001 e STIGLITZ, Joseph E. - 'Globalização - A Grande Desilusão'. 3. a ed. revista. Lisboa: Terramar, 2004. 
Durante muito tempo, a União Europeia orgulhou-se do seu modelo social, o denominado Estado-Providência, Welfare-State, Estado de bem-estar. Estas expressões resumem as políticas adoptadas pelos Estados, a fim de estes tomarem a seu cargo alguns dos acasos da existência humana, tornando-os responsáveis pela garantia de justiça social e coesão, situação que, até aqui, conferiu à União Europeia o seu traço distintivo mais marcante, tornando-se parte fundamental daquilo que a representa.

Mais recentemente, porém, as questões em torno da sustentabilidade daquele modelo sucedem-se, ante o desigual crescimento económico entre os Estados e persistência, nalguns, de uma alta taxa de desemprego ${ }^{8}$, gerando, a par de outros factores, desilusão e dúvida quanto ao projecto de uma Europa conjunta.

Neste contexto, 'pode, então, a Europa prescindir do seu modelo social?', perguntarão. A resposta parece ser negativa. Nessa medida, um debate alargado sobre uma reforma urgente do modelo em apreço, em ordem à revitalização do crescimento económico e resposta às alterações globais e internas, impõe-se.

O projecto europeu terá necessariamente de adaptar-se, delineando um programa de reformas inovador, que lhe permita continuar a gerar prosperidade e justiça, embora se reconheçam as dificuldades de implementação de reformas de tal envergadura, razão por que a maioria das inovações terá de ser introduzida, primeiro, a nível nacional ${ }^{9}$.

No respeitante à análise das tensões que afectam o modelo social europeu, é um equívoco focarmo-nos apenas no processo de globalização como único responsável pelas dificuldades sentidas, posto que os fenómenos de pobreza ${ }^{10}$, desigualdade ${ }^{11}$ e de

\footnotetext{
${ }^{8}$ Neste contexto é importante não esquecer o seguinte: quanto maior a proporção de pessoas empregadas, maior a disponibilidade monetária para o investimento social, apresentando-se o emprego, do mesmo passo, como o melhor instrumento para sair da pobreza.

${ }^{9}$ Para maiores desenvolvimentos quanto à desilusão ante o modelo social europeu e imperativo da respectiva reforma, v. GIDDENS, Anthony - 'A Europa na Era Global'. Lisboa: Presença, 2007.

${ }^{10}$ Numa primeira aproximação ao conceito diremos que a pobreza é uma realidade bem mais ampla e complexa do que um conjunto de carências materiais - as denominadas condições de vida objectivas - permite perceber. Daí que, a cabal compreensão do conceito imponha também a consideração do conjunto de condições que atingem o ser humano como um todo, na concretização da sua fundamental e universal vocação de desenvolvimento e realização. A complexidade do fenómeno explica a diversidade de compreensões acerca da pobreza, sendo certo que, na maior parte dos casos, as definições avançadas não são alternativas, mas antes complementares. Numa perspectiva, a pobreza identifica-se, como vimos, pelas necessidades materiais. Para outros, ela deve ser entendida como uma situação existencial para a qual concorrem também outros elementos, designadamente, de ordem psicológica, social e cultural. Noutro entendimento é atribuída importância fundamental aos conceitos de habilitação e de capacidade, em ordem a que a pessoa possa procurar o tipo de felicidade que tem razões para preferir. Numa compreensão nova e particularmente rica de SEN, Amartya - 'O desenvolvimento como liberdade', cit. (cf. supra, nt. 4), a pobreza associa-se à noção de (falta de) liberdade, configurando uma situação de negação de direitos humanos fundamentais, atendendo a que a afirmação da liberdade
} 


\title{
exclusão social ${ }^{12-13}$, que fazem perigar valores humanos capitais da nossa matriz
}

\author{
civilizacional, embora certamente afectados pela globalização, ao disseminar modos de
}

apenas tem sentido quando articulada com as condições efectivas do seu exercício. Por fim, a pobreza pode ser compreendida como uma situação de privação resultante de falta de recursos. Seguindo este pensamento, para que a pobreza seja solucionada não basta resolver a privação, compreendida como uma situação de carência, de não satisfação de necessidades humanas básicas, antes se torna imprescindível solucionar também a falta de recursos, em ordem a dada pessoa deixar de estar dependente de formas extraordinárias de ajuda (por exemplo, subsídios temporários, pensão social e rendimento social de inserção) e passar a ter como meio de vida um rendimento proveniente de uma das fontes tidas como normais e correntes na sociedade em que vive (no caso português, os rendimentos provenientes do trabalho - o salário - ou do capital - lucros, rendas e juros - e, ainda, as pensões de reforma ou de sobrevivência). Sobre as definições de pobreza, v. COSTA, Alfredo Bruto da (coord.); BAPTISTA, Isabel; PERISTA, Pedro; CARRILHO, Paula - 'Um olhar sobre a pobreza. Vulnerabilidade e exclusão social no Portugal Contemporâneo’. Lisboa: Gradiva, 2008, pp. 19, ss.. No respeitante ao caso português, os Autores concluem no sentido de que a pobreza continua, de modo geral, a ser compreendida como um fenómeno residual e periférico e que os programas de combate ao fenómeno têm sido, igual e maioritariamente, residuais e periféricos. Residuais, na medida em que constituem um acrescento marginal às políticas económicas e sociais. Periféricos, porquanto não atingem os factores estruturais que residem na sociedade dominante (p. 188). Nesta perspectiva, a pobreza, enquanto problema persistente da sociedade portuguesa, reclama soluções que dependem não apenas de políticas sociais, certamente indispensáveis, antes também da política económica.

${ }^{11}$ Aqui, a averiguação contende com o modo como dado volume de recursos é distribuído pelas unidades de análise (pessoas, famílias, agregados), mas já não com o modo como as parcelas que cabem a cada unidade se traduzem em níveis e condições de vida, nisto se distinguindo a desigualdade da pobreza que, ao invés, define-se, primariamente, com referência a níveis e condições de vida e, muito embora relacionada com a desigualdade, deve dela ser distinguida. Neste sentido, COSTA, Alfredo Bruto da (coord.); BAPTISTA, Isabel; PERISTA, Pedro; CARRILHO, Paula - 'Um olhar sobre a pobreza...', cit., pp. 52-53.

${ }^{12}$ Contradizer a exclusão social é um dos elementos, cuja contemplação impõe-se em ordem da criação de sociedades socialmente mais justas. A expressão exclusão social popularizou-se, de forma generalizada, para aludir à situação de grupos no fundo da escala socioeconómica, sendo certo que outros factores, que não apenas a pobreza, podem impedir os indivíduos ou grupos de participarem plenamente na sociedade. A fronteira entre a inclusão e a exclusão não é precisa, pelo que a exclusão há-de ser compreendida como um processo, que vai desde formas mais superficiais de exclusão para formas e graus mais profundos e abrangentes. Do mesmo passo, as diversas formas e factores de exclusão social podem sobrepor-se e, usualmente, sobrepõem-se - a denominada exclusão social múltipla. No respeitante aos factores que podem estar na origem de processos de exclusão encontramos factores de natureza social, afectando grupos que, devido ao modelo de organização da sociedade e estilos de vida dominantes, não têm lugar na sociedade em geral (v.g., o caso dos idosos), factores de origem legal, conexos com a relação dos indivíduos e dos diferentes grupos com o sistema político, designadamente ao nível da cidadania (v.g., o caso dos imigrantes), factores de natureza cultural e factores patológicos e de comportamentos autodestrutivos (pense-se, por exemplo, na doença psiquiátrica, no alcoolismo e na toxicodependência). Neste contexto, o facto de estarmos perante processos de exclusão com origens diferentes impõe que se pense em medidas e políticas particulares que combatam esses factores na sua origem de forma diferenciada. Sendo diversos os factores subjacentes a cada tipo de exclusão são também diferentes as soluções. Neste sentido, COSTA, Alfredo Bruto da (coord.); BAPTISTA, Isabel; PERISTA, Pedro; CARRILHO, Paula - 'Um olhar sobre a pobreza...', cit., pp. 72-74.

${ }^{13}$ Pobreza e exclusão social, embora estreitamente relacionadas, configuram realidades distintas. Assim, a pobreza adopta uma abordagem distributiva de cima para baixo, aquando da análise da sociedade, enquanto o conceito de exclusão social adopta uma perspectiva de dentro-para-fora, focandose, originária e predominantemente, na força dos laços sociais entre a pessoa e os grupos ou a sociedade. Em que consiste, então, a relação entre a exclusão social e a pobreza? Pelo simples facto de a pobreza implicar falta de recursos, ela representa alguma forma de exclusão social e a privação que a caracteriza denuncia, do mesmo passo, uma relação fraca ou em estado de ruptura com outros diversos sistemas sociais. Em resumo: a pobreza representa uma forma de exclusão social ou, dito doutro modo, não existe 
comparação competitiva entre as empresas e entre as sociedades, acentuando aquelas dificuldades, bem como ao retirar aos poderes nacionais a possibilidade de regularem e de artificializarem as relações económicas e sociais internas ${ }^{14}$, não deixam de ser igualmente influenciados pelas mudanças endógenas, em particular pelas transformações operadas na estrutura da família ${ }^{15}$, assim como por erro de concepção no dispositivo de segurança social e nas suas condições de financiamento, contribuindo, do mesmo passo, de modo relevante, para a imagem de perda dos poderes dos Estados nacionais $^{16}$.

\section{2. 'Renascer das cinzas'}

\subsection{Proposta de Habermas}

O aparente colapso do ideário europeu já suscitou uma resposta veemente de HABERMAS, no sentido de que nada está perdido e de que a Europa pode ter ainda futuro, apresentando-se a sua perspectiva, atenta a respectiva importância, como ponto de partida neste 'renascer das cinzas', com que iniciamos o presente ponto 2.

Contra a corrente de uma desastrosa desunião europeia, HABERMAS vem reivindicar mais Europa, propondo um modelo de democracia transnacional, em que o processo de unificação assoma dentro de um novo contexto civilizacional e de uma nova codificação do poder estatal, a saber, um projecto de constitucionalização do direito internacional, segundo o princípio jurídico de um direito cosmopolítico, cujo

pobreza sem exclusão social. O contrário, porém, não se afigura válido, posto que existem formas de exclusão social que não implicam pobreza. Pense-se, por exemplo, nos idosos ou nas várias formas de discriminação e preconceitos que excluem as minorias da sociedade, em que a exclusão não está necessariamente associada à pobreza. Sobre as relações entre pobreza e exclusão social, v. COSTA, Alfredo Bruto da (coord.); BAPTISTA, Isabel; PERISTA, Pedro; CARRILHO, Paula - 'Um olhar sobre a pobreza...', cit., pp. 62 , ss..

${ }^{14}$ Sobre o problema do impacto da globalização nos poderes e competências tradicionais dos estados nação no domínio económico, v. tb. CRAVINHO, J. Gomes - 'A Globalização e os Limites à Intervenção do Estado'. In 'O interesse Nacional e a Globalização', cit., pp. 85-95 e AMARAL, J. Ferreira do - 'Globalização e funções do Estado no domínio económico'. In 'O interesse Nacional e a Globalização’, cit., pp. 159-166, circunscrevendo-se a sua análise ao caso português.

${ }^{15}$ Pense-se, por exemplo, nas mais elevadas taxas de divórcio e nas mais baixas taxas de casamento.

${ }^{16}$ Em idêntico sentido, AQUIAR, Joaquim - 'Modelos de Globalização'. In 'O interesse Nacional e a Globalização', cit., pp. 79-80 e AMARAL, J. Ferreira do - 'Globalização e funções do Estado no domínio económico', cit., p. 165 ('a perda de poderes dos estados membros tem excedido as meras consequências da globalização. Por exemplo, nada na globalização impunha a perda de moeda própria'). 
referencial assenta na contemplação e respeito dos direitos humanos. Nas suas palavras, 'a dignidade humana é um sismógrafo que indica o que é constitutivo de uma ordem jurídica democrática ${ }^{17}$, seguindo, neste particular, a ideia de uma constituição civil e política que KANT já havia proposto em 1795, na sua obra 'A Paz Perpétua'18.

$\mathrm{Na}$ verdade, a afirmação central da protecção dos direitos humanos no ordenamento jurídico internacional e a correspondente erosão do tradicional domínio reservado aos Estados pode afirmar-se corresponder a uma das maiores alterações do direito internacional, sem prejuízo da necessidade sentida do seu contínuo reforço.

Culminar de uma evolução ${ }^{19}$, embora não necessariamente o seu fim, o artigo $6 .^{\circ}$ do Tratado da União Europeia constitui disposição-base quanto ao entendimento da Carta dos Direitos Fundamentais e do respectivo valor jurídico, consagrando o princípio da Comunidade de Direito ao determinar expressamente o reconhecimento pela União dos direitos, das liberdades e dos princípios ali enunciados ${ }^{20}$, afigurando-se, do mesmo passo, disposição central na afirmação e respeito pelos direitos humanos, aqui defendida.

Retomando agora o pensamento de HABERMAS, no lugar de uma Europa construída à porta fechada, emergente será transformá-la num espaço consubstancial a uma esfera pública.

'Em que termos?', perguntarão. Partindo daquela ideia de constitucionalização do direito internacional, a União Europeia apresentar-se-á como um importante instrumento na construção de uma sociedade mundial politicamente constituída, para uma comunidade dos Estados e dos cidadãos do mundo.

${ }^{17}$ HABERMAS, Jürgen - 'Um Ensaio sobre a Constituição da Europa'. Lisboa: Edições 70, 2012, p. 37.

${ }^{18}$ KANT, Immanuel - 'A paz perpétua. Um Projecto Filosófico', trad. de Artur Morão. Covilhã: Universidade da Beira Interior, Colecção Textos Clássicos de Filosofia, 2008. Disponível em http://www.lusosofia.net/textos/kant_immanuel_paz_perpetua.pdf.

19 A Carta dos Direitos Fundamentais começou por não existir, posto que os Tratados começaram por dirigir-se a objectivos de cariz eminentemente económico. Porém, a necessidade de se assinalarem os direitos fundamentais cedo acabou por surgir, mediante actuação dos tribunais nacionais, através do mecanismo de reenvio prejudicial (cf. actual artigo 267..$^{\text {) }}$. Quando primeiro chamado a averiguar da compatibilidade dos direitos fundamentais tal como consagrados nas ordens jurídicas nacionais com o direito comunitário, o Tribunal de Justiça entendeu não ter de se pronunciar. Mas se isto era assim, os tribunais nacionais reservavam-se o direito de aferir dessa compatibilidade. Daí que o Tribunal de Justiça viria, mais tarde, a mostrar-se sensível a esta necessidade, apelo e pressão dos tribunais nacionais.

${ }^{20}$ Porém, a Carta dos Direitos Fundamentais não se aplica de per si (cf. artigo 51. ${ }^{\circ}$ ). 
O projecto europeu há-de empenhar-se verdadeiramente na promoção e aprofundamento da noção de solidariedade, cuja afirmação naturalmente reclama um igual tratamento dos seus Estados, sem esquecer que tal empreendimento se traduz, numa dupla obrigação, a saber: a de tratamento igual no respeitante a situações iguais (proibição da discriminação) e a de tratamento diferenciado quanto situações diferentes (obrigação de diferenciação). Com efeito, um igual tratamento dos Estados impõe a contemplação das respectivas diferenças, sob pena de cairmos, mutatis mutandis, na alegoria de ORWELL, de que 'all animals are equal, but some animals are more equal than others' ('todos os animais são iguais, mas alguns são mais iguais do que outros') ${ }^{21}$. Ademais, uma Europa mais igualitária pode ser também uma Europa mais competitiva.

$\mathrm{Na}$ verdade, não podemos deixar de admitir que a crise instalada deve, em parte, a sua origem ao recuo da parcela de solidariedade, que foi sendo afirmada no decurso da existência da União Europeia.

Acompanhando o entendimento do Autor, o imperativo aprofundamento da solidariedade, ora em análise, não pode deixar de se fazer acompanhar de uma profunda revisão do Tratado de Lisboa, quer no sentido de dotar as instâncias comunitárias do poder para garantir a real convergência económica entre os Estados, quer de construir um novo equilíbrio entre as instituições, que permita reforçar o papel de intervenção dos Estados e dos seus cidadãos, tendo em vista assegurar, para o futuro, que o cumprimento dos compromissos assumidos resulte mais da convicção de se ser parte de um processo legitimador democrático e não tanto do receio das respectivas sanções por incumprimento.

Em ordem ao cumprimento do objectivo de promoção da solidariedade, o projecto europeu há-de promover também o crescimento económico, o desenvolvimento

${ }^{21}$ ORWELL, George - 'O Triunfo dos Porcos'. 4. ${ }^{\text {a }}$ ed. Mem-Martins: Publicações EuropaAmérica. Colecção Grandes Clássicos do seculo XX, vol. 20, 2005, relata-nos a história da revolução dos animais da quinta Manor, propriedade do senhor Jones, na sequência de reunião nocturna daqueles, promovida por Major, o mais respeitado porco, onde este atribui a responsabilidade das suas miseráveis existências à tirania dos homens que, preguiçosos e incompetentes, exploram, de modo prepotente, o seu trabalho. A revolução prossegue depois com novos líderes, Snowball, Napoleão e Squealer, porcos que criam o Animalismo, como sistema doutrinário, assente em 'Sete Mandamentos'. O regime do Animalismo inicia logo energicamente, com todos os animais a trabalharem, em vista da progressão da quinta, aparecendo a autogestão como estímulo do orgulho animal. Porém, com o passar do tempo, os porcos são corrompidos pela sede de poder, instalando-se, então, nova tirania, desta feita, sob o comando de Napoleão, segundo a máxima supra mencionada: 'Todos os animais são iguais, mas alguns são mais iguais do que outros'. Através da fábula, o Autor pretendeu, não apenas demonstrar como o idealismo foi atraiçoado pelo desejo de poder, corrupção e mentira, assim como condenar o totalitarismo, a Revolução Russa de 1917 e a Rússia de Stalin. 
sustentável e harmonioso dos Estados-membros, um alargamento da estrutura democrática para além das fronteiras nacionais, a existência de regras eleitorais e de um sistema partidário europeus, assim como a pertença a um colectivo político. E isto impõe-se, quanto a nós, mesmo em se reconhecendo o sentimento de desconfiança sentido pelos governos dos Estados ante a governança, enquanto processo complexo de tomada de decisão interactiva, dinâmica e projectiva, destinado a evoluir permanentemente para dar respostas a circunstâncias cambiantes, em que a contestação ou o exercício de uma influência não se afiguram já suficientes, antes se exigindo uma real participação dos cidadãos.

\subsection{Construção da cidadania e democracia europeias}

O imperativo da real participação dos cidadãos a que se aludiu pressupõe a consciência e perspectivação de um destino europeu, não já apenas nacional, assim como das respectivas consequências em termos de orientação política global ${ }^{22}$. Tendo em conta que matérias tão importantes como as da política militar, estratégica, monetária, social ou da emigração e emprego, passam agora necessariamente também pelo crivo da Europa, a ausência e desinteresse, até agora sentidos, há-de dar lugar à aludida participação e consciência.

Muito embora subordinada frequentemente às obstinações de modas intelectuais, por elas manipulada, por vezes, mesmo maltratada, a consciência de pertença à cidadania europeia apresenta-se, desta feita, como uma das principais ferramentas de construção, figurando a emergência de uma Europa cidadã como um dos leitmotivs mais retomados no discurso político, assim como nos debates de sociedade que, por respeitarem a cada habitante do continente, reclamam um acrescido esforço de interpretação e raciocínio no sentido de pensar uma cidadania, doravante, desligada da sua ancoragem nacional e com a riqueza de uma real singularidade.

22 Expressiva a este propósito é a passagem de LOURENÇO, Eduardo - 'A Europa Desencantada. Para uma Mitologia Europeia', 1. a ed. Lisboa: Gradiva, 2001, pp. 99-100: 'Curioso paradoxo da vida política nacional: habituados a pensar-nos «mundo», não conseguimos modular os nossos reflexos - fora da esfera económica - pela nova dimensão europeia. Talvez o nosso inconsciente imperial tenha alguma coisa a ver com esta «regionalização», ou este efectivo desinteresse em perspectivar o nosso destino caseiro em função de um destino europeu sentido mais como aleatório do que necessário. (...) Algum dia teremos de escolher - ou pelo menos de assumir com plena consciência entre duas opções a respeito do nosso destino nacional e da vida política que elas implicam'. 
Noção fundamental, ela é também ponto de partida para a reflexão em torno da própria natureza da democracia europeia nos seus parâmetros principais, a saber, a questão da amplitude dos direitos políticos e cívicos e o grau de participação política com que aquela deve ficar satisfeita ${ }^{23}$.

Neste contexto, o alinhamento de uma cidadania europeia por uma significação progressista dos direitos e deveres que recobre beneficiaria a transformação das instituições europeias, compreendidas não já como cabala, mas antes como autênticos sustentáculos de uma democracia social.

Além disso, o reforço da visão de uma construção europeia de sentido positivo impõe a valorização, por parte da própria União, da respectiva dimensão plural e reconhecimento das minorias ${ }^{24}$.

No respeitante à construção de uma democracia europeia, não deixaremos de reconhecer as dificuldades múltiplas, posto que a União, enquanto modelo sui generis ${ }^{25}$, assenta num jogo de procedimentos e de instituições particulares, fora dos trilhos delimitados pela experiência dos Estados unitários e dos Estados federais, frequentemente olhada com desconfiança pelos Estados ante o receio de perda da soberania nacional $^{26}$.

Duras críticas são ainda tecidas acerca do débil sustentáculo democrático dos mecanismos comunitários, atendendo, nomeadamente, ao lugar atribuído ao Parlamento Europeu, já compreendido, ante a insuficiência das suas prerrogativas, como o 'pálido sucedâneo' dos parlamentos nacionais ${ }^{27}$, além da diminuída atenção dada àquele por estes, do modo cerrado como são construídas as decisões políticas, assim como da ausência de clareza de dadas acções e da finalidade prosseguida pela União.

Urgente afigura-se, por conseguinte, a promoção da solidariedade entre o Parlamento Europeu e os parlamentos nacionais, assim como da transparência democrática, ambas até agora pouco exteriorizadas.

\footnotetext{
${ }^{23}$ Em idêntico sentido, WEYDERT, Jean; BÉROUD, Sophie - 'O Futuro da Europa', cit., p. 107.

24 Sobre a imperatividade de reconhecimento do pluralismo e direito das minorias, v. WEYDERT, Jean; BÉROUD, Sophie - 'O Futuro da Europa', cit., pp. 121-123.

${ }^{25}$ Recordando a expressão do antigo Presidente da Comissão, JACQUES DELORS, a União Europeia apresenta-se, mesmo hoje, como 'um objecto político não identificado'.

${ }^{26}$ Sobre a soberania dos Estados face à construção europeia, v. WEYDERT, Jean; BÉROUD, Sophie - 'O Futuro da Europa', cit., pp. 53-69.

${ }^{27}$ Neste sentido, WEYDERT, Jean; BÉROUD, Sophie - 'O Futuro da Europa', cit., p. 183.
} 
Neste contexto, o eixo franco-alemão, hoje mais mitigado, assim como as demais elites políticas que dominam as decisões da União Europeia devem favorecer a afirmação de uma vontade democrática comum, que defenda o interesse da comunidade internacional em que se insere.

\subsection{Respostas à crise do modelo social europeu}

Como vimos, um debate alargado sobre uma reforma urgente do modelo em apreço, em ordem à revitalização do crescimento económico e resposta às alterações globais e internas, impõe-se em ordem a contradizer a afirmação de que 'a Europa é hoje um oásis de paz e prosperidade num mundo onde se vislumbram largas «manchas» de fome e opressão, 28 .

Um dos aspectos a ser ponderado e, porventura, revisto, respeita ao financiamento do modelo social europeu por níveis relativamente altos de impostos, posto que já se constatou não existir uma relação directa entre aqueles e a proporção do PIB, o desenvolvimento económico ou a criação de emprego.

$\mathrm{Na}$ verdade, a economia deve servir o progresso e a justiça social ${ }^{29}$, posto que ‘a médio prazo, se não civilizarmos a economia, teremos de mudar de civilização, 30 .

Noção poderosa e abrangente, a justiça social compreende, em ordem à redução das desigualdades sociais e nivelamento das oportunidades de vida, a luta contra a pobreza $^{31}$, posto que esta limita a capacidade do indivíduo para a autonomia e autoestima; a criação de mais altos padrões de educação e formação, assentes em igualdade de acesso para todos; a salvaguarda de emprego àqueles que querem e podem trabalhar; a protecção de um sistema de providência que ofereça protecção e dignidade; a

${ }^{28}$ Observação efectuada já em 1990 por MELLO, M. J. Homem de - 'Portugal, a Europa e o Futuro'. Editorial Notícias. Colecção Sinal dos Tempos, 1990, p. 49.

${ }^{29}$ ARNAUT, António - 'Identidade, Indispensabilidade e Sustentabilidade do Serviço Nacional de Saúde', Intervenção no Congresso de Medicina Interna, 2012. Disponível em http://www.fnam.pt/antigo/informacao/infromacao_files/IDENTIDADE_INDISPENSABILIDADE_SUS TENTABILIDADE.pdf, p. 15.

${ }^{30}$ SANTOS, Boaventura Sousa - 'Portugal - Ensaio Contra a Autoflagelação'. Coimbra: Almedina, 2011, p. 154.

${ }^{31}$ Sobre o conceito de pobreza, cf. supra, nt. 10. 
limitação das desigualdades ${ }^{32}$ de rendimento e de riqueza, na medida em que obstem à realização daquelas primeiras metas ou puserem em risco a coesão social.

Como refere ARNAUT, a primazia concedida ao capital financeiro aprisionou a soberania dos Estados, reduzindo dados governantes à mera 'condição de serventuários', sufocados que estão pela dívida potenciada pelos próprios especuladores, assim como pelos seus partidos, agora comutados em 'máquinas trituradoras das boas intenções de alguns', por 'clientelas vorazes e impiedosas' e pelos interesses predominantes, carecendo a muitos 'compreensão pelo sofrimento do povo, pela humilhação dos excluídos e sem trabalho', o 'sentido do bem-comum' e a 'vibração patriótica e solidária'.

Propugna o Autor pela libertação do Estado da tutela do poder económico e recuperação das suas funções sociais e reguladoras, imprescindíveis ao desenvolvimento, ao decoro cívico, à paz e união entre os portugueses, posto que a austeridade 'cega, dura e crua' não pode exceder as fronteiras humanamente toleráveis e alcançar 'a desumanidade da opressão', sob pena de apenas a revolta poder libertar os oprimidos, quando 'nesse então já nada haverá a perder' 33 .

Neste contexto, a continuidade do projecto europeu implica o reconhecimento de que os Estados isolados não logram resolver os seus problemas e a admissão de que é urgente que os cidadãos europeus se responsabilizem e olhem uns pelos outros.

Outro aspecto que não deixa aqui de exercer influência é o da pressão dos mercados financeiros, instituições incontornáveis, não apenas dos sistemas financeiros, como também das nossas sociedades, com reflexos notórios na vida quotidiana dos indivíduos $^{34}$, ante a extrema ambiguidade do seu papel, funcionando, por um lado, como grande revelador, penalizando qualquer Estado que não observe dadas regras tidas por fundamentais no mundo contemporâneo; por outro, como grande desestabilizador,

\footnotetext{
${ }^{32}$ Sobre a distinção entre pobreza e desigualdade, cf. supra, nt. 11.

${ }^{33}$ ARNAUT, António - 'Identidade, Indispensabilidade e Sustentabilidade do Serviço Nacional de Saúde', cit., pp. 10-11.

${ }^{34}$ Interessante a este propósito é o texto de TERLICA, Sofia; COELHO, Bernardo - 'Mercados financeiros: instituições ocultas e dinâmicas invisíveis'. In DORNELAS, António; OLIVEIRA, Luísa; VELOSO, Luísa; GUERREIRO, Maria das Dores (organizadores) - 'Portugal Invisível'. Lisboa: Editora Mundos Sociais, 2010, pp. 7-51 que, mediante uma análise da realidade que transpõe as fronteiras nacionais, destacam o facto de estarem aqui em causa instituições incontornáveis, não apenas dos sistemas financeiros, como também das nossas sociedades, com reflexos notórios na vida quotidiana dos indivíduos, propondo uma reflexão económica e sociológica centrada nas agências de rating como 'caixas negras', cuja revelação contribuiria certamente para uma clarificação da arquitectura dos sistemas financeiros.
} 
por não terem logrado uma nova ordem e estruturas financeiras capazes de fazerem face à progressiva diversidade de todo o sistema, encontrando-se actualmente numa fase de transição, conforme o demonstra a crise instalada ${ }^{35}$.

\subsection{Papel decisivo do Direito}

Neste contexto, o Direito, conforme já demos a antever ao leitor, não deixará certamente de cumprir o seu papel, sobretudo se atendermos a que esta é uma época marcada por constantes mutações sociais que compreensivelmente não deixam de actuar também no domínio desta área do saber.

Também a geografia do Direito que, desde a era moderna associamos ao Estado e ao seu território, está em mudança, construindo-se agora em espaços alargados, como sucede no espaço europeu ou até à escala do globo.

O processo de europeização, que começa pela produção de conteúdos normativos dirigidos a enquadrar e regular o processo de integração, extravasa agora o seu âmbito económico original, a saber, o do mercado comum, para penetrar em campos «clássicos», como o direito civil e o direito penal ${ }^{36}$, até há pouco imunes aos esforços de harmonização.

Assim, a noção de europeização, em matéria jurídica, abre portas à análise, não apenas do direito emanado da União Europeia - o denominado direito europeu -, antes também da sua interacção com os direitos nacionais, assim como dos condicionantes desta influência recíproca, designadamente factores sociais, económicos, culturais e institucionais.

Por via da coordenação, da harmonização ou da uniformização legislativa estimulada pelas instituições europeias, os direitos nacionais adaptam-se e modificamse, sendo certo que a impregnação no direito interno pelo direito europeu não se faz sem obstáculos, em razão da natural tensão entre o direito europeu e os direitos

\footnotetext{
${ }^{35}$ Neste sentido, BARROSO, J. M. Durão - 'O interesse nacional e a globalização', cit., p. 132.

${ }^{36}$ Pense-se, a título de exemplo, no mandato de detenção europeu.
} 
constitucionais nacionais e resistência de juristas perante a mudança ou o risco de perda de identidade das respectivas culturas jurídicas. Desta feita, a europeização revelar-se-á mais ou menos eficaz em função da maior ou menor proximidade dos sistemas internos em relação ao sistema europeu.

Pelo exposto, quer o processo de europeização, quer o de globalização ${ }^{37}$, apelam à revisão de teorias e metodologias de análise tradicionais, que tendiam a encarar os direitos nacionais como sistemas fechados, esperando-se agora, da ciência jurídica que se abra à consideração dos novos territórios do direito - a Europa, o globo - e às mudanças que aqueles vêm imprimindo nos conteúdos legislativos, assim como nos modos de produzir e praticar o Direito ${ }^{38}$.

\section{Conclusão}

Muito embora, como disse o poeta António Machado, 'se hace camino al andar' ('o caminho faz-se caminhando'), isso não significa indiferença quanto à direcção dos primeiros passos, posto que esta há-de condicionar toda a jornada.

Como vimos, os conceitos de sociedade de risco, de globalização e de europeização impõem o reconhecimento de que Portugal não se encontra já 'orgulhosamente só'. Tão-pouco a União Europeia se encontra.

Neste contexto, o projecto europeu há-de empenhar-se na promoção da noção de solidariedade, a par do crescimento económico e do desenvolvimento sustentável e harmonioso dos Estados-membros, em ordem à resolução da crise do modelo social europeu. Ademais, o alargamento da estrutura democrática para além das fronteiras nacionais, a existência de regras eleitorais e de um sistema partidário europeus, assim como a pertença a um colectivo político, impõem-se, apresentando-se aqui a cidadania europeia como uma das principais ferramentas de construção, figurando a emergência de uma Europa cidadã como um dos leitmotivs mais retomados no discurso político, assim como nos debates de sociedade. Noção fundamental, ela é também ponto de partida para a reflexão em torno da própria natureza da democracia europeia nos seus

\footnotetext{
${ }^{37}$ Para maiores desenvolvimentos acerca do conceito de globalização e seus desafios, v. supra, ponto 1.2

38 Para maiores desenvolvimentos, v. GONÇALVES, Maria Eduarda; GUIBENTIF, Pierre 'Novos Territórios do Direito: Europeização, Globalização e Transformação da Regulação Jurídica'. São João do Estoril: ISCTE: Instituto Superior de Ciências do Trabalho e da Empresa, Principia, 2008.
} 
parâmetros principais, posto que o alinhamento de uma cidadania europeia por uma significação progressista dos direitos e deveres que recobre beneficiaria a transformação das instituições europeias, compreendidas não já como cabala, mas antes como autênticos sustentáculos de uma democracia social, tudo aspectos em que o Direito não deixará de exercer um papel decisivo.

Naturalmente a reflexão aqui empreendida em torno da União Europeia não esgota todas as questões que poderiam e podem ser suscitadas, reclamando a temática um contínuo aprofundamento dos dados ora lançados, sobretudo se atendermos a que esta é uma época marcada por constantes mutações a nível do globo, que compreensivelmente não deixam de actuar também aqui.

Porém, uma observação é certa: mais do que garante a todo o custo da moeda única, a União Europeia deve tornar-se um espaço de liberdade, de participação, de solidariedade e de respeito e promoção dos direitos fundamentais dos seus cidadãos.

\section{Bibliografia}

AMARAL, J. Ferreira do - 'Globalização e funções do Estado no domínio económico'. In TEIXEIRA, Nuno Severiano (coord.) - 'O interesse Nacional e a Globalização'. Lisboa: Edições Cosmos, Instituto da Defesa Nacional, 2000, pp. 159166.

AQUIAR, Joaquim - 'Modelos de Globalização'. In TEIXEIRA, Nuno Severiano, coord. - 'O interesse Nacional e a Globalização'. Lisboa: Edições Cosmos, Instituto da Defesa Nacional, 2000, pp. 57-83.

ARNAUT, António - 'Identidade, Indispensabilidade e Sustentabilidade do Serviço Nacional de Saúde', Intervenção no Congresso de Medicina Interna, 2012. Disponível em http://www.fnam.pt/antigo/informacao/infromacao_files/IDENTIDADE_INDISPENSA BILIDADE_SUSTENTABILIDADE.pdf 
BARRETO, António; LEITE, António Nogueira; DOLLAR, David; GYIMAHBOADI, E.; MAYOR, Federico; FUKUYAMA, Francis; ESPADA, João Carlos; SAMPAIO, Jorge; SOETE, Luc; BARBOSA, Manuel Pinto; MOREIRA, Marcílio Marques; JOHNSTON, Michael; WALLE, Nicolas van de; JOHNSON, Pierre Marc; BALDWIN, Robert. E; MCKINNON, Ronald; REBELO, Sérgio; ROSE-ACKERMAN, Susan; MACHADO, Víctor de Sá; ANDERSON, Walter Truett - 'Globalização, Desenvolvimento e Equidade'. Lisboa: Fundação Calouste Gulbenkian, Publicações Dom Quixote, 2001

BARROSO, J. M. Durão - 'O interesse nacional e a globalização'. In TEIXEIRA, Nuno Severiano (coord.) - 'O interesse Nacional e a Globalização'. Lisboa: Edições Cosmos, Instituto da Defesa Nacional, 2000, pp. 129-141.

BECK, Ulrich - 'Risk Society. Towards a New Modernity'. London: Theory, Culture \& Society Series, Sage, 1992.

COSTA, Alfredo Bruto da (coord.); BAPTISTA, Isabel; PERISTA, Pedro; CARRILHO, Paula - 'Um olhar sobre a pobreza. Vulnerabilidade e exclusão social no Portugal Contemporâneo'. Lisboa: Gradiva, 2008.

CRAVINHO, J. Gomes - 'A Globalização e os Limites à Intervenção do Estado'. In TEIXEIRA, Nuno Severiano (coord.) - 'O interesse Nacional e a Globalização'. Lisboa: Edições Cosmos, Instituto da Defesa Nacional, 2000, pp. 85-95.

GIDDENS, Anthony - ‘A Europa na Era Global’. Lisboa: Presença, 2007.

GONÇALVES, Maria Eduarda; GUIBENTIF, Pierre - 'Novos Territórios do Direito: Europeização, Globalização e Transformação da Regulação Jurídica'. São João do Estoril: ISCTE: Instituto Superior de Ciências do Trabalho e da Empresa, Principia, 2008

HABERMAS, Jürgen - 'Um Ensaio sobre a Constituição da Europa'. Lisboa: Edições 70, 2012. 
KANT, Immanuel - 'A paz perpétua. Um Projecto Filosófico', trad. de Artur Morão. Covilhã: Universidade da Beira Interior, Colecção Textos Clássicos de Filosofia, $2008 . \quad$ Disponível em http://www.lusosofia.net/textos/kant_immanuel_paz_perpetua.pdf.

LOURENÇO, Eduardo - 'A Europa Desencantada. Para uma Mitologia Europeia', 1. ed., Lisboa, Gradiva, 2001.

MELLO, Manuel José Homem de - 'Portugal, a Europa e o Futuro'. Editorial Notícias. Colecção Sinal dos Tempos, 1990.

MONGIARDIM, Maria Regina - 'O Alargamento da União Europeia - Novos Vizinhos'. Lisboa: Prefácio, 2004.

MURTEIRA, Mário - 'Globalização - Pela invenção dum tempo global e solidário’. Lisboa: Quimera, 2003.

ORWELL, George - 'O Triunfo dos Porcos'. 4. a ed. Mem-Martins: Publicações Europa-América. Colecção Grandes Clássicos do seculo XX, vol. 20, 2005.

SANTOS, Boaventura Sousa - 'Portugal - Ensaio Contra a Autoflagelação'. Coimbra: Almedina, 2011.

SEN, Amartya - 'O desenvolvimento como liberdade'. Lisboa: Gradiva, 2003.

STIGLITZ, Joseph E. - 'Globalização - A Grande Desilusão'. 3. a ed. revista. Lisboa: Terramar, 2004.

TERLICA, Sofia; COELHO, Bernardo - 'Mercados financeiros: instituições ocultas e dinâmicas invisíveis'. In DORNELAS, António; OLIVEIRA, Luísa; VELOSO, Luísa; GUERREIRO, Maria das Dores (organizadores)- 'Portugal Invisível'. Lisboa: Editora Mundos Sociais, 2010, pp. 7-51. 
WEYDERT, Jean / BÉROUD, Sophie - 'O Futuro da Europa'. Porto: Colecção Que futuro?, Ambar, 2002 